\title{
End-diastolic flow reversal limits the efficacy of pediatric intra-aortic balloon pump counterpulsation
}

\author{
Carlo R. Bartoli, MD, PhD, ${ }^{\mathrm{a}, \mathrm{b}}$ Benjamin D. Rogers, MS, ${ }^{\mathrm{c}}$ Constantine E. Ionan, MD, ${ }^{\mathrm{d}}$ and \\ George M. Pantalos, $\mathrm{PhD}^{\mathrm{d}, \mathrm{e}, \mathrm{f}}$
}

Background: Counterpulsation with an intra-aortic balloon pump (IABP) has not achieved the same success or clinical use in pediatric patients as in adults. In a pediatric animal model, IABP efficacy was investigated to determine whether IABP timing with a high-fidelity blood pressure signal may improve counterpulsation therapy versus a low-fidelity signal.

\begin{abstract}
Methods: In Yorkshire piglets $(\mathrm{n}=19$; weight, $13.0 \pm 0.5 \mathrm{~kg})$ with coronary ligation-induced acute ischemic left ventricular failure, pediatric IABPs $(5$ or $7 \mathrm{~mL})$ were placed in the descending thoracic aorta. Inflation and deflation were timed with traditional criteria from low-fidelity (fluid-filled) and high-fidelity (micromanometer) blood pressure signals during 1:1 support. Aortic, carotid, and coronary hemodynamics were measured with pressure and flow transducers. Myocardial oxygen consumption was calculated from coronary sinus and arterial blood samples. Left ventricular myocardial blood flow and end-organ blood flow were measured with microspheres.
\end{abstract}

Results: Despite significant suprasystolic diastolic augmentation and afterload reduction at heart rates of $105 \pm$ 3 beats per minute, left ventricular myocardial blood flow, myocardial oxygen consumption, the myocardial oxygen supply/demand relationship, cardiac output, and end-organ blood flow did not change. Statistically significant end-diastolic coronary, carotid, and aortic flow reversal occurred with IABP deflation. Inflation and deflation timed with a high-fidelity versus low-fidelity signal did not attenuate systemic flow reversal or improve the myocardial oxygen supply/demand relationship.

Conclusions: Systemic end-diastolic flow reversal limited counterpulsation efficacy in a pediatric model of acute left ventricular failure. Adjustment of IABP inflation and deflation timing with traditional criteria and a high-fidelity blood pressure waveform did not improve IABP efficacy or attenuate flow reversal. Enddiastolic flow reversal may limit the efficacy of IABP counterpulsation therapy in pediatric patients with traditional timing criteria. Investigation of alternative deflation timing strategies is warranted. (J Thorac Cardiovasc Surg 2014;147:1660-7)

Counterpulsation with an intra-aortic balloon pump (IABP) is the most common mechanical circulatory support strategy for a variety of cardiac pathologies in adults. ${ }^{1}$ Yet, IABP therapy in pediatric patients has not demonstrated the same degree of efficacy and has not gained widespread

From the Division of Cardiovascular Surgery, ${ }^{\text {a }}$ University of Pennsylvania, Philadelphia, $\mathrm{Pa}$; the $\mathrm{MD} / \mathrm{PhD}$ Program, ${ }^{\mathrm{b}}$ University of Louisville School of Medicine, Louisville, Ky; the University of Louisville School of Medicine, ${ }^{\mathrm{c}}$ Louisville, Ky; and the Cardiovascular Innovation Institute, ${ }^{\mathrm{d}}$ and the Departments of Bioengineering ${ }^{\mathrm{e}}$ and Surgery, ${ }^{\mathrm{f}}$ University of Louisville, Louisville, Ky.

This study was supported by grants from the National Heart, Lung, and Blood Institute (1-R01-HL61696) and the Jewish Hospital Research Foundation (Louisville, Ky) and also by Kosair Charities Pediatric Heart Research Laboratories (Louisville, Ky). The Cardiac Assist Division of Datascope Corporation (Fairfield, NJ) donated the intra-aortic balloon pump catheters and console used in this study.

Disclosures: Authors have nothing to disclose with regard to commercial support.

Received for publication May 21, 2013; revisions received Aug 6, 2013; accepted for publication Aug 16, 2013; available ahead of print Oct 17, 2013.

Address for reprints: George M. Pantalos, PhD, Cardiovascular Innovation Institute, University of Louisville, 302 E Muhammad Ali Blvd, Room 410, Louisville, KY 40202 (E-mail: gmpant02@louisville.edu).

$0022-5223 / \$ 36.00$

Copyright (c) 2014 by The American Association for Thoracic Surgery

http://dx.doi.org/10.1016/j.jtcvs.2013.08.044 clinical use. ${ }^{2}$ Differences between adult and pediatric anatomy and physiology may limit the efficacy of IABP therapy in neonates, infants, and children.

In this study, we examined IABP counterpulsation in a pediatric model of acute ischemic left ventricular failure. We tested the hypothesis that the efficacy of pediatric IABP therapy is improved with a high-fidelity (micromanometer) rather than a traditional low-fidelity (fluid-filled) arterial blood pressure signal used to adjust IABP inflation and deflation timing.

\section{METHODS}

All animals received humane care and were handled in accordance with the Guide for the Care and Use of Laboratory Animals (National Research Council, 1996). Experimental procedures followed animal study protocols approved by the University of Louisville (Louisville, Ky) Institutional Animal Care and Use Committee.

\section{Experimental Design}

Piglets ( $\mathrm{n}=19$; weight, $13.0 \pm 0.5 \mathrm{~kg}$ ) were instrumented surgically to determine aortic, carotid, and coronary artery hemodynamics. Myocardial oxygen consumption $\left(\mathrm{MVO}_{2}\right)$ was calculated from coronary sinus and arterial blood gas data. Left ventricular myocardial blood flow and regional 

Abbreviations and Acronyms
AoF $=$ aortic flow
AoP $=$ aortic pressure
$\mathrm{bpm}=$ beats per minute
IABP $=$ intra-aortic balloon pump
LAD $=$ left anterior descending
$\mathrm{LADF}=\mathrm{LAD}$ flow
$\mathrm{LAP}=$ left atrial pressure
LVP $=$ left ventricular pressure
$\mathrm{MVO}_{2}=$ myocardial oxygen consumption

end-organ blood flow were determined with neutron-activated $15-\mu \mathrm{m} \mathrm{mi-}$ crospheres. Sequential coronary ligation was performed to induce acute ischemic left ventricular failure. A pediatric IABP was placed in the descending thoracic aorta.

In each animal, hemodynamic waveforms (15-second data epochs), blood gases, and end-organ blood flows were measured at steady state during the following experimental test conditions: (1) normal baseline (IABP off), (2) coronary ligation-induced left ventricular failure (IABP off), (3) IABP support with timing adjusted to the arterial blood pressure waveform acquired with a low-fidelity $(<20-\mathrm{Hz}$ response) fluid-filled catheter in the radial artery, and (4) IABP support with timing adjusted to the arterial pressure waveform acquired with a high-fidelity $(<5-\mathrm{kHz}$ response) micromanometer pressure transducer in the aortic root. Measurements were recorded during 1:1 counterpulsation support in which each aortic valve closure initiated rapid balloon inflation and each end diastole initiated rapid balloon deflation.

Of note, an aortic root pressure waveform transduced by a high-fidelity catheter results in a more precise waveform morphology with a more pronounced dicrotic notch, less signal gain, and less phase distortion. ${ }^{3}$ Consequently, a high-fidelity signal was presumed to enable more accurate inflation and deflation timing of the IABP.

\section{Surgical Preparation}

Animals were fasted, preanesthetized with intramuscular ketamine (30 $\mathrm{mg} / \mathrm{kg})$ and acepromazine $(0.2 \mathrm{mg} / \mathrm{kg})$, and anesthetized with isoflurane $(1.5 \%-3 \%)$ and room air. A left lateral thoracotomy was performed, and the left and right carotid artery and jugular vein were exposed through neck incisions. A single-tip high-fidelity micromanometer catheter $(2.5$ Fr, SPR-524; Millar Instruments, Houston, Tex) was placed in the left atrium. A dual-tip high-fidelity micromanometer catheter (5 Fr, SPC721; Millar Instruments) was advanced retrograde from the ascending aorta into the left ventricle. Transit-time ultrasonic flow probes (T205; Transonics, Ithaca, NY) were placed around the aortic root, left carotid artery, and left anterior descending (LAD) coronary artery to measure volumetric blood flows. Sampling catheters were introduced into the coronary sinus via the hemiazygous vein, pulmonary artery, and right carotid artery to sample blood and measure blood gases. An infusion catheter was introduced into the left atrium for serial injections of microspheres during each experimental test condition to determine end-organ blood flows throughout the body. ${ }^{4}$ A blood-sampling catheter was introduced into the right femoral artery for simultaneous withdrawal of a microsphere reference blood-flow sample during each test condition. A fluid-filled pressure-monitoring catheter (24-gauge Angiocath; Becton Dickinson, Sandy, Utah) was inserted into the right radial artery.

The animal was anticoagulated with a bolus injection of heparin (300 U/ $\mathrm{kg}$ ) and subsequent small boluses of heparin to maintain an activated clotting time of greater than 300 seconds. An IABP catheter ( 5 or $7 \mathrm{~mL}$; Datascope, Fairfield, NJ) was inserted via a left femoral artery cut down and advanced until the tip was distal to the left subclavian artery, as confirmed by digital palpation. Balloon timing was manually adjusted with the arterial pressure waveform (fluid-filled radial artery catheter or aortic root Millar catheter) displayed on the IABP console (System 97; Datascope). Balloon inflation and deflation were timed to maximize aortic diastolic pressure augmentation and minimize aortic end-diastolic pressure (afterload).

\section{Induction of Ischemic Left Ventricular Failure}

Intravenous lidocaine (20-mg bolus, 20-mg/h infusion) and esmolol (5-mg/kg bolus, $50-\mu \mathrm{g} / \mathrm{kg}$ per minute infusion) were administered to prevent arrhythmia. Sequential coronary ligation of branches of the LAD induced acute ischemic left ventricular failure. Target cardiac dysfunction was achieved when 3 of 4 criteria were met: approximate reduction of (1) left ventricular cardiac output by $25 \%$, (2) mean aortic pressure by $10 \mathrm{~mm}$ $\mathrm{Hg}$, (3) mixed venous $\mathrm{O}_{2}$ saturation by $10 \%$, and (4) an elevation of left atrial pressure (LAP) and/or left ventricular end-diastolic pressure by 5 $\mathrm{mm} \mathrm{Hg}$. Animals with life-threatening hypotension were supported with boluses of intravenous normal saline and continuous infusion of phenylephrine and/or epinephrine to effect.

\section{Blood Gas Analysis}

During each experimental test condition, blood samples were simultaneously withdrawn from the coronary sinus, pulmonary artery, and right carotid artery. Samples were processed with a blood gas analyzer (IRMA Blood Analysis System; Diametrics Medical, Roseville, Minn) to measure hemoglobin content $([\mathrm{Hb}] \mathrm{g} / \mathrm{dL})$ and hemoglobin oxygen saturation $\left(\% \mathrm{O}_{2}\right.$ Sat). Oxygen content $\left(\left[\mathrm{O}_{2}\right]\right)$ was calculated for each blood sample:

$$
\begin{aligned}
{\left[\mathrm{O}_{2}\right] } & =\frac{\% \mathrm{O}_{2} \mathrm{Sat} \times[\mathrm{Hb}] \times \mathrm{O}_{2} \text { capacity of } \mathrm{Hb}\left(1.34 \mathrm{ml} \mathrm{O}_{2} / \mathrm{g}\right)}{100} \\
& =\left[\mathrm{mL} \mathrm{O}_{2} / 100 \mathrm{~mL}\right]
\end{aligned}
$$

Total myocardial oxygen consumption $\left(\mathrm{MVO}_{2}\right)$ was calculated as follows:

$$
\mathrm{MVO}_{2}=\left(\left[\mathrm{O}_{2}\right]_{\mathrm{a}}\right)-\left(\left[\mathrm{O}_{2}\right]_{\mathrm{cs}}\right) \times \mathrm{MBF}=[\mathrm{mL} / \mathrm{min} / \mathrm{g}]
$$

$\left[\mathrm{O}_{2}\right]_{\mathrm{a}}=$ arterial oxygen content, $\left[\mathrm{O}_{2}\right]_{\mathrm{cs}}=$ coronary sinus oxygen content, $\mathrm{MBF}=$ total myocardial blood flow in $\mathrm{mL} / \mathrm{min} / 100 \mathrm{~g}$ as determined by the microsphere method.

\section{End-Organ Blood Flow Measurements}

During each experimental test condition, a different color (isotope label) of $15-\mu \mathrm{m}$ neutron-activated microspheres $\left(1 \times 10^{6}\right.$ microspheres in $0.4-\mathrm{mL}$ suspension; Biopal, Worcester, Mass) was injected into the left atrium, followed by a $4-\mathrm{mL}$ saline flush. The microsphere technique enabled the measurement of regional end-organ blood flow in vascular beds of interest, as previously described. ${ }^{4,5}$ During microsphere injection, a reference bloodflow sample was drawn from the femoral artery at a rate of $4 \mathrm{~mL} / \mathrm{min}$ for 60 seconds with a calibrated syringe pump (Harvard Apparatus, Holliston, Mass). The withdrawal sample acted as a reference to determine organspecific flows in $\mathrm{mL} / \mathrm{min}$ per gram of tissue. ${ }^{4}$

\section{Necropsy and Microsphere Analysis}

After completion of the experimental protocol, animals were euthanized with an increase in anesthetic depth and an intravenous bolus injection of supersaturated $\mathrm{KCl}$. After euthanasia, the heart was harvested and weighed. The ventricles were dissected from the atria. The left ventricle was dissected from the right ventricle. The brain, lungs, kidneys, pancreas, liver, spleen, and adrenals were harvested and weighed.

Tissue and reference blood samples were sent to BioPAL, Inc (Worcester, Mass) for radioactive assay and automated calculation of blood flow in $\mathrm{mL} /$ min per gram for each sample during each experimental test condition. Tissue and blood samples were bombarded with neutrons to transiently activate each 
TABLE 1. Hemodynamic measurements in a pediatric model of left ventricular failure during IABP support

\begin{tabular}{|c|c|c|c|c|c|c|c|c|}
\hline Variable & $\begin{array}{l}\text { HR, } \\
\text { bpm }\end{array}$ & $\begin{array}{c}\text { LADF }_{\text {mean }}, \\
\mathrm{mL} / \mathrm{min}\end{array}$ & $\begin{array}{c}\text { LVCO, } \\
\text { L/min }\end{array}$ & $\begin{array}{c}\text { AoP }_{\text {mean }}, \\
\mathrm{mm} \mathrm{Hg}\end{array}$ & $\begin{array}{c}\mathbf{L A P}_{\text {mean }}, \\
\mathrm{mm} \mathbf{H g}\end{array}$ & $\begin{array}{c}\text { LVP }_{\text {end-diastolic }} \\
\text { mm Hg } \\
\end{array}$ & $\begin{array}{c}\text { L kidney, } \\
\text { mL/min } \\
\text { per gram }\end{array}$ & $\begin{array}{c}\text { Mixed } \\
\text { venous } \\
\mathrm{O}_{2}, \% \\
\end{array}$ \\
\hline Baseline & $107 \pm 4$ & $26 \pm 4$ & $2.30 \pm 0.17$ & $67 \pm 4$ & $9 \pm 1$ & $9 \pm 1$ & $1.69 \pm 0.29$ & $86 \pm 1$ \\
\hline LV failure & $104 \pm 3$ & $16 \pm 3^{*}$ & $1.67 \pm 0.15^{*}$ & $53 \pm 3^{*}$ & $12 \pm 1^{*}$ & $14 \pm 1^{*}$ & $0.90 \pm 0.13 *$ & $70 \pm 4 *$ \\
\hline 1:1 low-fidelity IABP & $105 \pm 3$ & $18 \pm 3$ & $1.78 \pm 0.15$ & $56 \pm 3$ & $11 \pm 1$ & $14 \pm 1$ & $0.99 \pm 0.22$ & $74 \pm 4$ \\
\hline 1:1 high-fidelity IABP & $107 \pm 3$ & $19 \pm 3$ & $1.84 \pm 0.15$ & $56 \pm 3$ & $11 \pm 1$ & $12 \pm 2$ & $1.01 \pm 0.15$ & $70 \pm 5$ \\
\hline
\end{tabular}

$H R$, Heart rate; $b p m$, beats per minute; $L A D F$, left anterior descending coronary artery flow; $L V C O$, left ventricular cardiac output; $A o P$, aortic pressure; $L A P$, left atrial pressure; $L V P$, left ventricular pressure; $L$, left; $L V$, left ventricular; $I A B P$, intra-aortic balloon pump. $* P<.05$ versus baseline.

group of microspheres with a separate isotope label. The level of radioactivity detected in the sample was directly proportional to the number of microspheres present in the sample. The activity of microspheres in the reference blood sample was compared with the activity of microspheres that lodged in a tissue sample of interest. The ratio between the 2 activity counts was equal to the ratio between the calibrated rate of aortic withdrawal (known, $4 \mathrm{~mL} / \mathrm{min}$ ) and flow in the tissue of interest (unknown).

\section{Instrumentation, Data Reduction, and Statistics}

All transducers were precalibrated and postcalibrated against known physical standards to ensure measurement accuracy. Collected data were signal conditioned $(1000 \times$ gain and $60-\mathrm{Hz}$ low-pass filter) and analog- to-digital converted at a sampling rate of $400 \mathrm{~Hz}$ for digital analysis using our Good Laboratory Practices-compliant data acquisition system. ${ }^{6}$

Hemodynamic parameters were calculated on a beat-to-beat basis for each 15-second data set with the Hemodynamic Evaluation and Assessment Research Tool program ${ }^{7}$ developed in Matlab, version 6.5 (MathWorks, Natick, Mass). All analyzed beats in each data set (approximately $25-30$ beats/15-second data set) were averaged to obtain a single representative mean value for each calculated parameter.

Pressure and flow waveforms were used to derive the following hemodynamic parameters: heart rate, aortic pressure (AoP), left atrial pressure (LAP), left ventricular pressure (LVP), aortic flow (AoF), carotid artery flow, and LAD flow (LADF). Left ventricular myocardial blood flow, as
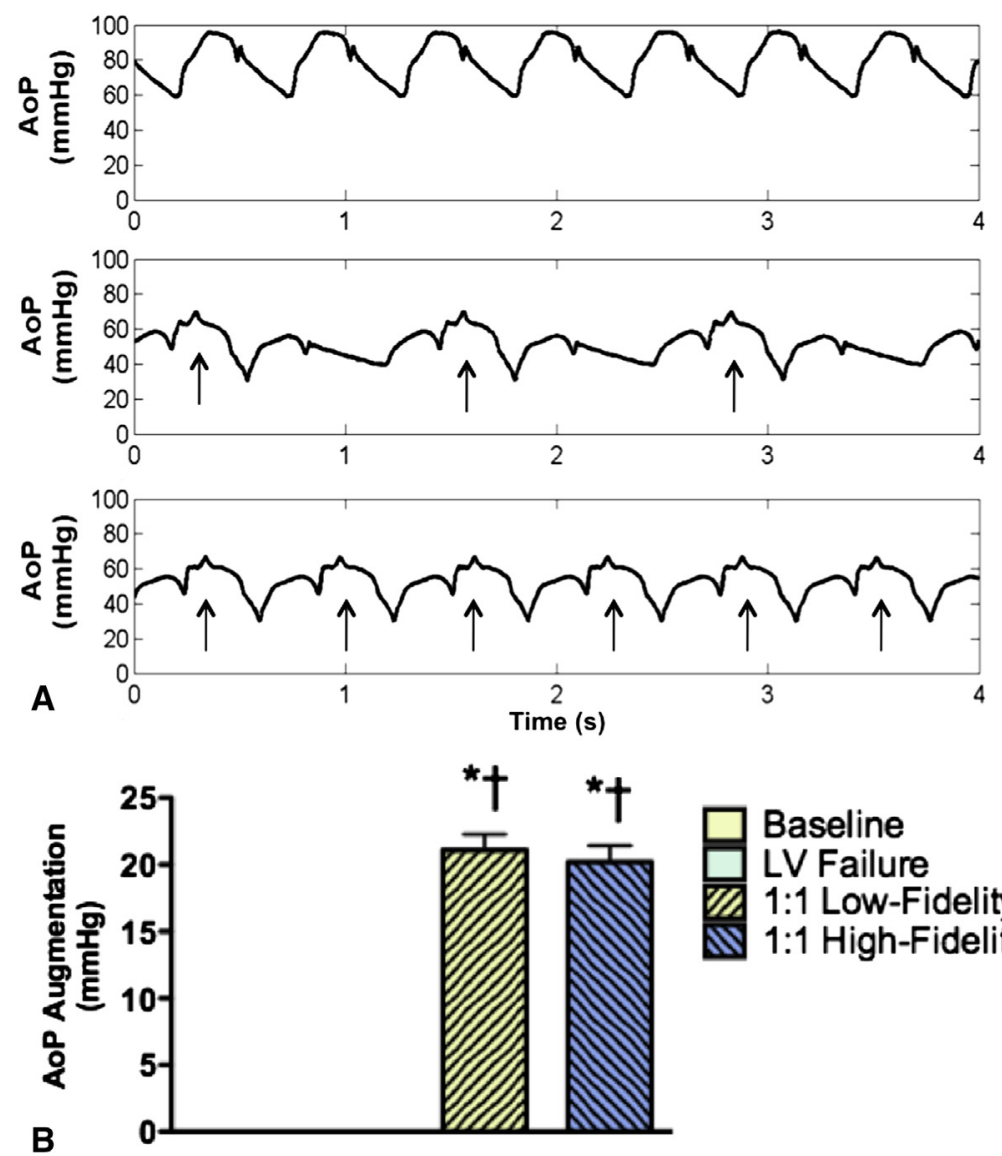

FIGURE 1. A, Aortic root pressure waveforms from the same animal demonstrated suprasystolic diastolic augmentation and afterload reduction during 1:2 (middle panel) and 1:1 (bottom panel) intra-aortic balloon pump (IABP) support compared with baseline (top panel). Arrows indicate supported beats. B, Diastolic augmentation of greater than $20 \mathrm{~mm} \mathrm{Hg}$ was achieved when the IABP was timed with a low-fidelity (fluid-filled) catheter in the radial artery or a high-fidelity (micromanometer) catheter in the aorta. AoP, Aortic pressure; $L V$, left ventricular. ${ }^{*} P<.0001$ versus baseline; $\dagger P<.0001$ versus LV failure. 

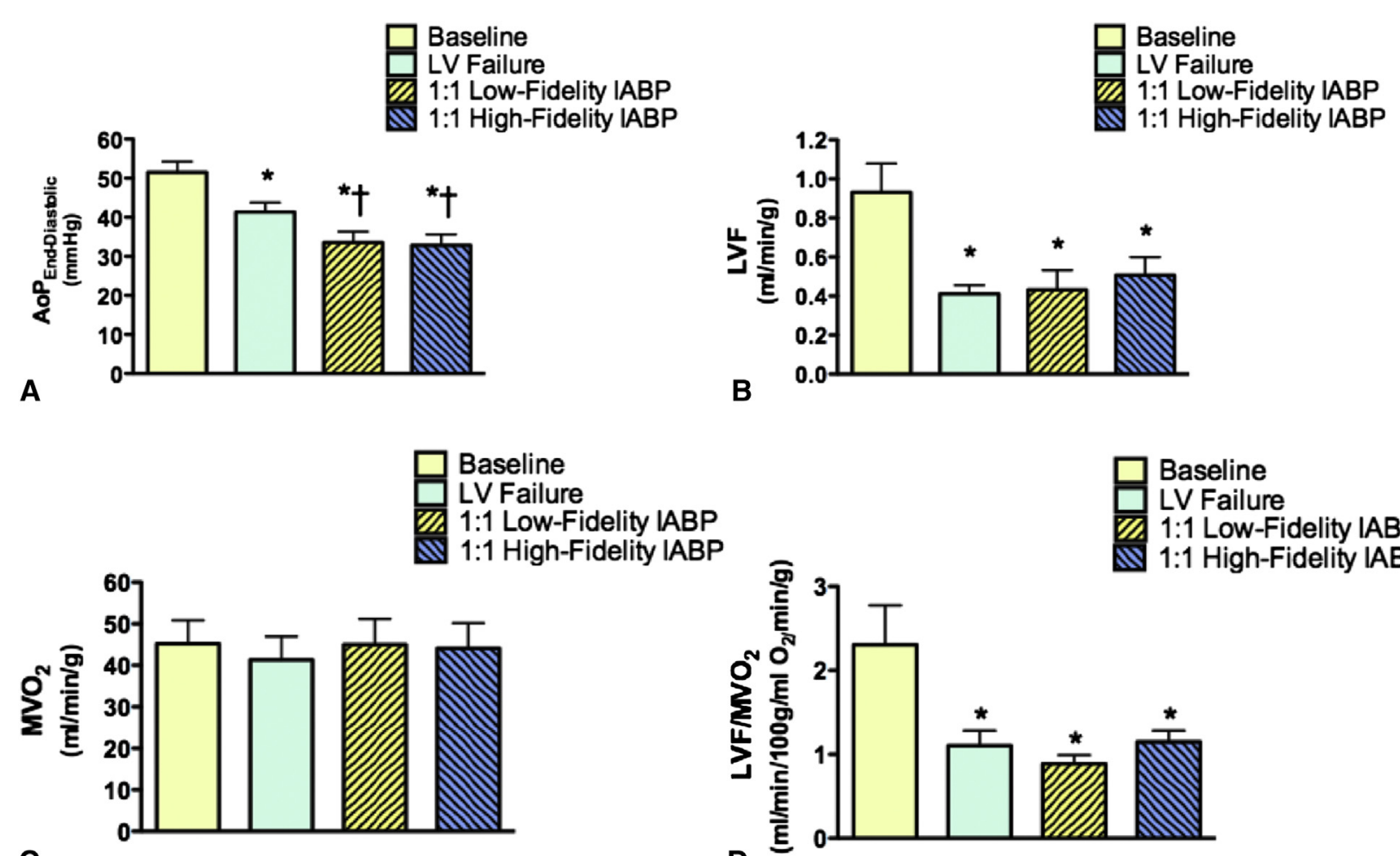

Baseline

LV Failure

1:1 Low-Fidelity IABP 1:1 High-Fidelity IABP

\section{C}

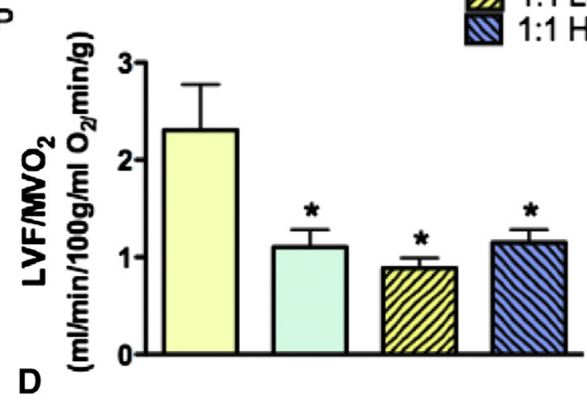

FIGURE 2. A, End-diastolic aortic pressure $(A o P)$ was significantly reduced during 1:1 intra-aortic balloon pump $(I A B P)$ therapy timed with a low-fidelity (fluid-filled) catheter in the radial artery or a high-fidelity (micromanometer) catheter in the aorta. B, Left ventricular myocardial blood flow ( $L V F)$ did not improve significantly during 1:1 IABP therapy timed with either a low-fidelity or a high-fidelity blood pressure signal. C, Myocardial oxygen consumption $\left(\mathrm{MVO}_{2}\right)$ did not improve during 1:1 IABP therapy timed with either a low-fidelity or a high-fidelity blood pressure signal. $\mathrm{D}, \mathrm{LVF}$ normalized to $\mathrm{MVO}_{2}$, an index of the myocardial oxygen supply/demand relationship, did not significantly improve during 1:1 IABP therapy timed with either a low-fidelity or a high-fidelity blood pressure signal. $L V$, Left ventricular. $* P<.01$ versus baseline; $\dagger P<.05$ versus LV failure.

determined by microspheres normalized to $\mathrm{MVO}_{2}$ was used as an index of the oxygen supply/demand relationship.

Prism, version 4.00 (GraphPad, La Jolla, Calif), was used to perform statistical analyses and to plot data. To verify the induction of a clinically relevant state of left ventricular failure, paired Student $t$ tests were used to compare values for LADF, AoF, AoP, mixed venous $\mathrm{O}_{2}$ saturation, end-organ blood flows, LAP, and LVP at baseline and after coronary ligation. A 1-way repeated-measures analysis of variance with a Tukey posttest for comparison of means was performed to compare left ventricular failure and IABP timing modes (low and high fidelity) for each parameter. $P<.05(95 \%$ confidence) was considered statistically significant. All data were presented as mean \pm SE.

\section{RESULTS}

\section{Model of Pediatric Left Ventricular Failure}

Of the 19 piglets, 10 completed the experimental protocol. In these animals, LAD ligation produced ischemic left ventricular failure with phenotypic similarities to clinical left ventricular failure (Table 1). Animals exhibited an approximate reduction in $\mathrm{LADF}_{\text {mean }}$ by $40 \%(26 \pm 4$ to $16 \pm 3 \mathrm{~mL} / \mathrm{min}, P<.01)$, AoF by $30 \%(2.4 \pm 0.2$ to $1.7 \pm 0.2 \mathrm{~L} / \mathrm{min}, P<.001)$, AoP ${ }_{\text {mean }}$ by $15 \mathrm{~mm} \mathrm{Hg}(67 \pm$ 4 to $53 \pm 3 \mathrm{~mm} \mathrm{Hg}, P<.01$ ), mixed venous $\mathrm{O}_{2}$ saturation by $15 \%(86 \% \pm 1 \%$ to $70 \% \pm 4 \%, P<.001)$, renal blood flow by $45 \%$ to $50 \%$ (left kidney: $1.69 \pm 0.29$ to $0.90 \pm$ $0.13 \mathrm{~mL} / \mathrm{min}$ per $100 \mathrm{~g}, P<.05$; right kidney: $2.13 \pm$ 0.45 to $1.02 \pm 0.18 \mathrm{~mL} / \mathrm{min}$ per $100 \mathrm{~g}, P<.05$ ), an increased LAP by approximately $3 \mathrm{~mm} \mathrm{Hg}(9 \pm 1$ to 12 $\pm 1, P<.001)$, and $\mathrm{LVP}_{\text {end-diastolic }}$ by approximately 5 $\mathrm{mm} \mathrm{Hg}(9 \pm 1$ to $14 \pm 1, P<.01)$.

The other 9 animals died before completion of the study protocol, typically from intractable arrhythmia. Data from these animals were not included in any of the analyses.

\section{Diastolic Augmentation and Left Ventricular Afterload Reduction}

At heart rates of $105 \pm 3$ beats per minute (bpm; range, $83-125 \mathrm{bpm}$ ), it was possible to achieve statistically significant suprasystolic diastolic pressure augmentation during each native cardiac beat (Figure 1, A, bottom waveform). During 1:1 IABP support timed with a low-fidelity (fluidfilled) or a high-fidelity (micromanometer) blood pressure signal, similar aortic pressure augmentation of greater than $20 \mathrm{~mm} \mathrm{Hg}$ was observed (Figure $1, B, P<.0001$ ).

Significant left ventricular afterload reduction, as indicated by aortic end-diastolic pressure, was also achieved 

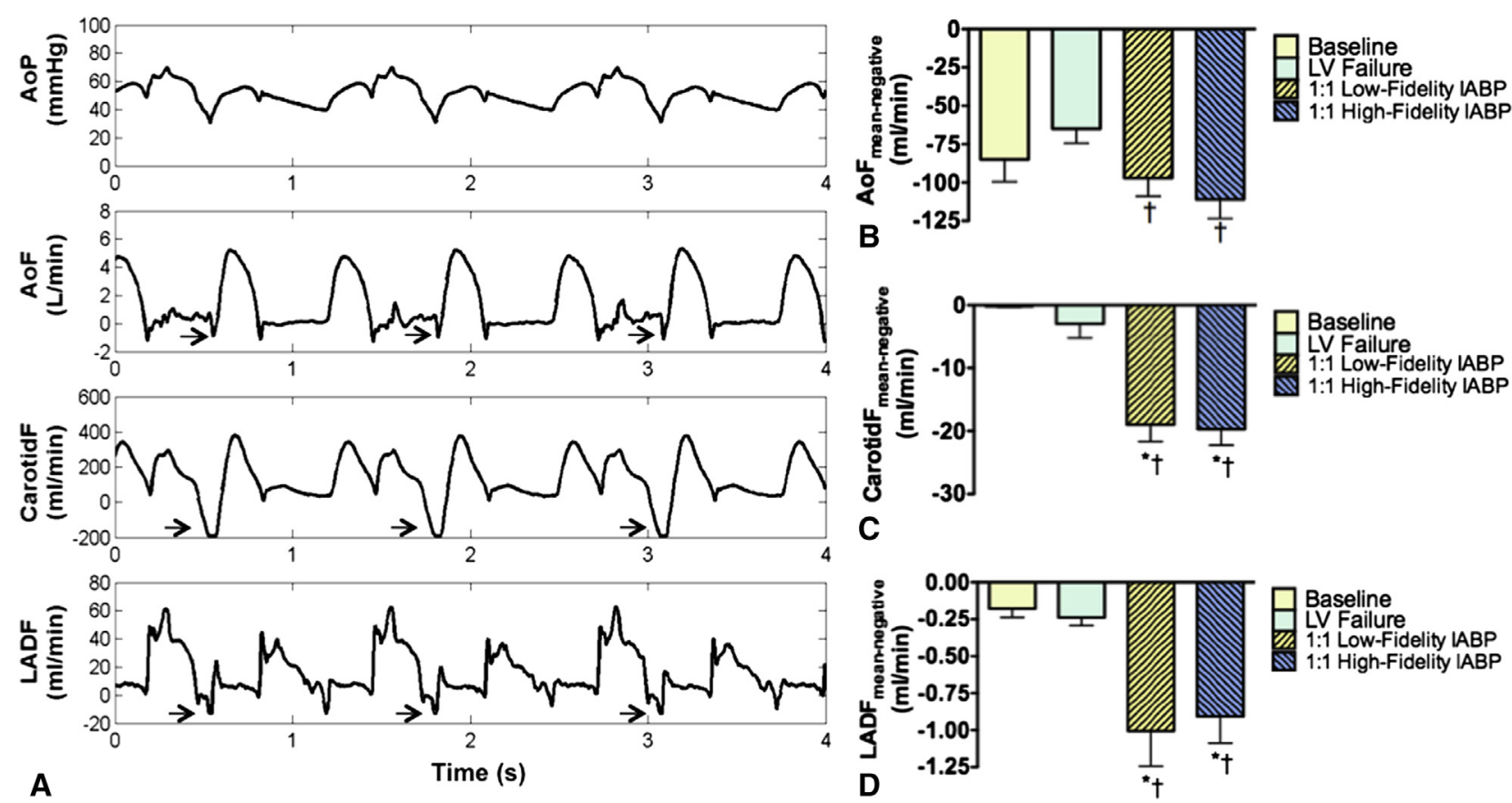

FIGURE 3. A, Hemodynamic waveforms from the same animal during intra-aortic balloon pump (IABP) support demonstrated suprasystolic diastolic augmentation and afterload reduction (top panel). Rapid balloon deflation and the decrease in end-diastolic blood pressure produced aortic, carotid, and left anterior descending $(L A D)$ coronary artery flow reversal. Arrows indicate periods of flow reversal. Waveforms show 1:2 IABP support to illustrate that flow reversal is not present with unsupported beats. B, Aortic flow $(A o F)$ reversal increased significantly during 1:1 IABP support. C, Carotid flow $($ CarotidF) reversal increased significantly during 1:1 IABP support. D, LAD flow ( $L A D F)$ increased significantly during 1:1 IABP support. B-D, Flow reversal was not attenuated in any artery during 1:1 IABP therapy timed with a low-fidelity (fluid-filled) catheter in the radial artery or a high-fidelity (micromanometer) catheter in the aorta. AoP, Aortic pressure; $L V$, left ventricular. $* P<.01$ versus baseline; $\uparrow P<.05$ versus $L V$ failure.

(Figure 1, A, middle and bottom waveforms; and Figure 2, A). During 1:1 IABP support, aortic end-diastolic pressure decreased by approximately $8 \mathrm{~mm} \mathrm{Hg}$ (left ventricular failure, $41 \pm 2 \mathrm{~mm} \mathrm{Hg}$; low-fidelity signal, $34 \pm 3 \mathrm{~mm} \mathrm{Hg}[P<.0001]$; high-fidelity signal, $33 \pm 3 \mathrm{~mm} \mathrm{Hg}[P<.0001])$. The increase in left ventricular myocardial blood flow during IABP support was small and did not reach statistical significance with either a low- or high-fidelity blood pressure signal (Figure 2, B). Similarly, myocardial oxygen consumption did not change during 1:1 IABP support with either a low- or high-fidelity blood pressure signal (Figure 2,C). As a result, despite suprasystolic diastolic augmentation and left ventricular afterload reduction, the myocardial oxygen supply/demand relationship did not significantly improve with either a low-fidelity or a high-fidelity signal to adjust IABP inflation and deflation timing (Figure 2, D).

\section{Systemic Flow Reversal}

Brief, but statistically significant, end-diastolic flow reversal occurred in the aorta, carotid artery, and LAD (Figure 3). During 1:1 IABP support, mean flow reversal in the aorta increased by approximately $40 \mathrm{~mL} / \mathrm{min}$ (left ventricular failure, $-65 \pm 10 \mathrm{~mL} / \mathrm{min}$; low-fidelity signal, $-97 \pm 12 \mathrm{~mL} / \mathrm{min}[P<.0001]$; high-fidelity signal, -111 $\pm 12 \mathrm{~mL} / \mathrm{min}[P<.0001])$. Mean flow reversal in the carotid artery increased by approximately $15 \mathrm{~mL} / \mathrm{min}$ (left ventricular failure, $-3 \pm 2 \mathrm{~mL} / \mathrm{min}$; low-fidelity signal, $-19 \pm 3$ $\mathrm{mL} / \mathrm{min}[P<.0001]$; high-fidelity signal, $-20 \pm 3 \mathrm{~mL} /$

TABLE 2. End-organ blood flow in a pediatric model of left ventricular failure during IABP support

\begin{tabular}{lcccccc}
\hline \multicolumn{1}{c}{$\begin{array}{c}\text { ANOVA } \\
\boldsymbol{P} \text { value }\end{array}$} & $\begin{array}{c}\text { L cerebrum, } \\
\mathbf{~ m L / m i n} \\
\text { per gram }\end{array}$ & $\begin{array}{c}\text { R cerebrum, } \\
\mathbf{m L} / \mathbf{m i n} \\
\text { per gram }\end{array}$ & $\begin{array}{c}\text { Cerebellum, } \\
\mathbf{m L} / \mathbf{m i n} \\
\text { per gram }\end{array}$ & $\begin{array}{c}\text { Brainstem, } \\
\mathbf{m L} / \mathbf{m i n} \\
\text { per gram }\end{array}$ & $\begin{array}{c}\text { L lung, } \\
\mathbf{m L} / \mathbf{m i n} \\
\text { per gram }\end{array}$ & $\begin{array}{c}\text { R lung, } \\
\mathbf{m L} / \mathbf{m i n} \\
\text { per gram }\end{array}$ \\
\hline Baseline & $0.31 \pm 0.08$ & $0.28 \pm 0.07$ & $0.62 \pm 0.08$ & $0.42 \pm 0.10$ & $1.99 \pm 0.48$ \\
Left ventricular failure & $0.26 \pm 0.05$ & $0.24 \pm 0.04$ & $0.35 \pm 0.03^{*}$ & $0.39 \pm 0.08$ & $0.96 \pm 0.20^{*}$ & $0.98 \pm 0.21^{*}$ \\
1:1 low-fidelity IABP & $0.36 \pm 0.09$ & $0.35 \pm 0.07$ & $0.38 \pm 0.06$ & $0.28 \pm 0.08$ & $1.14 \pm 0.27$ & $1.02 \pm 0.29$ \\
1:1 high-fidelity IABP & $0.33 \pm 0.07$ & $0.30 \pm 0.06$ & $0.43 \pm 0.06$ & $0.38 \pm 0.11$ & $1.16 \pm 0.24$ & $1.14 \pm 0.23$ \\
\hline
\end{tabular}

ANOVA, Analysis of variance; $L$, left; $R$, right; IABP, intra-aortic balloon pump. $* P<.05$ versus baseline. 
$\min [P<.0001])$. Mean flow reversal in the LAD increased by approximately $0.70 \mathrm{~mL} / \mathrm{min}$ (left ventricular failure, $-0.24 \pm 0.06 \mathrm{~mL} / \mathrm{min}$; low-fidelity signal, $-1.01 \pm 0.24$ $\mathrm{mL} / \mathrm{min}[P<.0001]$; high-fidelity signal, $-0.91 \pm 0.18$ $\mathrm{mL} / \mathrm{min}[P<.0001])$.

\section{End-Organ Blood Flow}

Cardiac output (LVCO) did not significantly improve during 1:1 IABP support (left ventricular failure, $1.67 \pm 0.15 \mathrm{~L} / \mathrm{min} ;$ low-fidelity signal, $1.78 \pm 0.15$ $\mathrm{L} / \mathrm{min}$; high-fidelity signal, $1.84 \pm 0.15 \mathrm{~L} / \mathrm{min}$ ). As a result, systemic end-organ blood flow did not significantly improve with 1:1 IABP support timed with a low- or a high-fidelity blood pressure signal (Table 2).

\section{DISCUSSION}

Pediatric patients with life-threatening heart failure present difficult clinical challenges. During the past 5 decades, the intra-aortic balloon pump (IABP) has successfully supported pediatric patients with congenital and acquired heart disease as a bridge to decision, cardiac transplantation, and recovery. Yet, mortality rates greater than $35 \%^{2,8,9}$ and the lowest long-term survival for any pediatric mechanical circulatory support modality ${ }^{10}$ indicate a need to improve the efficacy of pediatric IABP therapy.

In this study, in a piglet model of acute left ventricular failure, 1:1 IABP counterpulsation was possible at high heart rates. However, brief systemic blood flow reversal coincident with IABP deflation may have limited the efficacy of IABP support. Despite significant suprasystolic diastolic augmentation and significant left ventricular afterload reduction during 1:1 IABP support, left ventricular myocardial blood flow, myocardial oxygen consumption, and the myocardial oxygen supply/demand relationship did not improve. Cardiac output and end-organ blood flow also did not significantly improve. A brief, but significant, flow reversal in conduit arteries may have limited systemic forward flow. Traditional IABP inflation and deflation timing with a high-fidelity trigger did not attenuate flow reversal or improve IABP efficacy. These findings suggest that enddiastolic flow reversal is an important and novel mechanism that may limit the efficacy of IABP counterpulsation in pediatric patients with traditional inflation and deflation criteria.

\section{Clinical Considerations}

The optimal timing of pediatric IABP inflation and deflation is uncertain. ${ }^{11,12}$ In any patient with an IABP, it is traditionally thought that inflation and deflation of the balloon must occur during diastole between closure of the aortic valve and the subsequent systole. In an adult patient, this timing paradigm typically is not difficult to achieve. However, pediatric patients have higher heart rates than adults (newborn, 120-160 bpm; infant/toddler, 90-130 bpm), and diastole is short. As heart rate increases, diastole becomes disproportionally shorter. ${ }^{13}$ As a result, inflation and deflation of the balloon must occur within a smaller window of time. From the current study, we speculate that the short duration of diastole during high heart rates may limit the hemodynamic benefits of IABP inflation. Correspondingly, rapid balloon deflation produces a sharp reduction in aortic end-diastolic blood pressure and brief flow reversal sufficient to limit net augmentation of coronary blood flow or improve the myocardial oxygen supply/demand relationship.

Indeed, in adult patients, balloon deflation may produce a steep reduction of central end-diastolic blood pressure that may lead to a "steal" phenomenon during which coronary, ${ }^{14,15}$ carotid, ${ }^{15,16}$ cerebral, $^{17}$ and aortic ${ }^{15,18}$ blood flow reverse. In adults, flow reversal is brief, and net flow augmentation is still positive. However, in a pediatric patient with a high heart rate, forward flow from diastolic augmentation occurs over a shorter period, and rapid balloon deflation occurs more frequently. As a result, the ratio between flow reversal and augmented forward flow is greater and may limit maximum net forward flow.

Importantly, coronary flow reversal may be attenuated by adjusting inflation and deflation timing. ${ }^{14}$ In adults with a normal heart rate $(60-80 \mathrm{bpm})$, sufficient time exists between each systole to allow a brief (up to 25-millisecond) deflation delay, which may reduce flow reversal. As a result, subtle variations in the timing of inflation and deflation may permit an incremental tradeoff between afterload and myocardial workload reduction versus diastolic augmentation and coronary perfusion. Unfortunately, in pediatric patients, high heart rates with a shorter diastole minimize the available window to delay deflation for this tradeoff.

Similarly, brief timing errors associated with a fluid-filled versus a high-fidelity signal ${ }^{12}$ or a high-fidelity signal versus

TABLE 2. Continued

\begin{tabular}{|c|c|c|c|c|c|c|}
\hline $\begin{array}{c}\text { L kidney, } \\
\mathrm{mL} / \mathrm{min} \\
\text { per gram }\end{array}$ & $\begin{array}{c}\text { R kidney, } \\
\text { mL/min } \\
\text { per gram }\end{array}$ & $\begin{array}{c}\text { Pancreas, } \\
\mathrm{mL} / \mathrm{min} \\
\text { per gram }\end{array}$ & $\begin{array}{c}\text { Liver, } \\
\text { mL/min } \\
\text { per gram }\end{array}$ & $\begin{array}{c}\text { Spleen, } \\
\text { mL/min } \\
\text { per gram }\end{array}$ & $\begin{array}{c}\text { L adrenal, } \\
\mathrm{mL} / \mathrm{min} \\
\text { per gram }\end{array}$ & $\begin{array}{c}\mathrm{R} \text { adrenal, } \\
\mathrm{mL} / \mathrm{min} \\
\text { per gram }\end{array}$ \\
\hline $1.69 \pm 0.31$ & $2.13 \pm 0.45$ & $0.29 \pm 0.08$ & $0.52 \pm 0.20$ & $1.14 \pm 0.22$ & $0.88 \pm 0.33$ & $0.83 \pm 0.35$ \\
\hline $0.90 \pm 0.13^{*}$ & $1.02 \pm 0.18^{*}$ & $0.22 \pm 0.05$ & $0.21 \pm 0.06$ & $0.41 \pm 0.07^{*}$ & $0.41 \pm 0.04$ & $0.39 \pm 0.08$ \\
\hline $0.99 \pm 0.22$ & $1.02 \pm 0.20$ & $0.20 \pm 0.04$ & $0.23 \pm 0.05$ & $0.50 \pm 0.15$ & $0.56 \pm 0.11$ & $0.52 \pm 0.12$ \\
\hline $1.01 \pm 0.15$ & $1.20 \pm 0.18$ & $0.19 \pm 0.04$ & $0.36 \pm 0.08$ & $0.54 \pm 0.09$ & $0.62 \pm 0.14$ & $0.63 \pm 0.13$ \\
\hline
\end{tabular}


echocardiographic timing ${ }^{19}$ may reduce counterpulsation efficacy in pediatric patients. A precise signal is required to accurately time inflation and deflation and maximize counterpulsation efficacy in pediatric patients. To this end, integration of a high-fidelity micromanometer into the catheter tip may eliminate timing error(s), especially compared with low-fidelity fluid-filled catheters, which introduce gain and phase distortion and tend to drift over time. ${ }^{20}$ Indeed, we $^{19}$ observed that it was easier to identify inflation and deflation timing landmarks in the arterial pressure waveform acquired with a high-fidelity signal. Consequently, timing errors were unlikely responsible for end-diastolic flow reversal. In our study, adjustment of IABP timing with a high-fidelity blood pressure signal (that minimized timing error) did not significantly reduce end-diastolic flow reversal or improve hemodynamics or end-organ blood flow compared with a low-fidelity signal. This finding further supports the notion that balloon inflation and deflation with traditional timing criteria triggered by a highfidelity arterial blood pressure signal are insufficient to improve counterpulsation therapy in pediatric patients. Instead, the development of alternative timing strategies are necessary to prevent end-diastolic flow reversal and improve IABP efficacy in pediatric patients.

\section{Other Considerations}

Counterpulsation therapy is most effective when the displaced blood volume of the balloon and the left ventricular stroke volume are similar. ${ }^{21,22}$ In this study, we used 5- and 7-mL IABPs, which are the clinically recommended sizes for an 8- to $18-\mathrm{kg}$ infant. ${ }^{23}$ However, the stroke volume of a 12-kg piglet (and a 12-kg human) with left ventricular failure is approximately 15 to $17 \mathrm{~mL}$, more than 3 times the displacement volume of these IABPs. This observation begs the question of whether a larger balloon (and a larger displaced blood volume) may produce greater diastolic pressure augmentation to significantly improve diastolic coronary blood flow. By the same token, rapid deflation of a balloon with a larger volume may produce a greater decrease in end-diastolic aortic blood pressure and further increase the volume of blood flow reversal. This hypothesis remains untested. However, from a technical standpoint, the size of peripheral arteries in pediatric patients may limit the size of the balloon catheter that may be safely inserted and preclude counterpulsation therapy with a larger-sized IABP.

Arterial compliance also plays an important role in counterpulsation therapy. It has been demonstrated in vitro, ${ }^{24}$ experimentally in animal studies, ${ }^{25}$ and clinically ${ }^{26}$ that the efficacy of counterpulsation therapy correlates inversely with arterial compliance. Specifically, stiffer arteries generate the greatest diastolic augmentation and reduction in end-diastolic blood pressure. As a result, it has been speculated that the high compliance of the pediatric aorta may limit IABP efficacy. ${ }^{27}$ This effect has not been rigorously defined. Moreover, there is evidence to the contrary that the compliance of the pediatric aorta ${ }^{28}$ is sufficient to produce diastolic augmentation, afterload reduction, and improved hemodynamics. ${ }^{27}$ Our results further support this point.

\section{Future Investigations}

Ongoing studies will determine whether alternative timing strategies, such as delayed balloon deflation, may improve the efficacy of pediatric counterpulsation. Similarly, the use of larger pediatric balloons with greater displacement volumes that are more comparable to native stroke volume may improve the efficacy of pediatric IABP counterpulsation.

\section{CONCLUSIONS}

An incomplete understanding of counterpulsation has limited the widespread application of IABPs in pediatric patients. In a piglet model of acute ischemic left ventricular failure, significant diastolic augmentation and afterload reduction were achieved with a pediatric IABP at high heart rates. However, significant aortic, carotid, and coronary blood flow reversal, coincident with balloon deflation during end diastole, reduced net systemic forward flow. IABP inflation and deflation timed with traditional criteria and a high-fidelity blood pressure signal did not attenuate flow reversal or improve IABP efficacy. These findings suggest that brief end-diastolic flow reversal is an important and novel mechanism that may limit the effectiveness of IABP counterpulsation in pediatric patients with traditional inflation and deflation criteria.

The authors acknowledge and thank Laura and Karen Lott (animal preparation), Cary Woolard (instrumentation preparation), Kevin Gillars (analog hemodynamic data acquision), and the University of Louisville Research Resource Center veterinary staff for their assistance with animal experiments. Dr Steven Koenig, Dr Kevin Soucy, and Dr Guruprasad Giridharan contributed to the coronary flow reversal hypothesis ${ }^{14}$ and to data analysis. Dr Michael Mitchell contributed to the data analysis. Dr Steven Koenig and Dr Mark Slaughter provided funding for summer medical student participation (BDR). Dr Steven Koenig also participated in the review and revision of manuscript drafts.

\section{References}

1. Ferguson JJ III, Cohen M, Freedman RJ Jr, Stone GW, Miller MF, Joseph DL, et al. The current practice of intra-aortic balloon counterpulsation: results from the Benchmark Registry. J Am Coll Cardiol. 2001;38:1456-62.

2. Collison SP, Dagar KS. The role of the intra-aortic balloon pump in supporting children with acute cardiac failure. Postgrad Med J. 2007;83:308-11.

3. Pantalos GM, Koenig SC, Gillars KJ, Haugh GS, Dowling RD, Gray LA Jr. Intraaortic balloon pump timing discrepancies in adult patients. Artif Organs. 2011;35:857-66.

4. Bartoli CR, Okabe K, Akiyama I, Coull B, Godleski JJ. Repeat microsphere delivery for serial measurement of regional blood perfusion in the chronically instrumented, conscious canine. J Surg Res. 2008;145:135-41. 
5. Bartoli CR, Wead WB, Giridharan GA, Prabhu SD, Koenig SC, Dowling RD. Mechanism of myocardial ischemia with an anomalous left coronary artery from the right sinus of Valsalva. J Thorac Cardiovasc Surg. 2012;144:402-8.

6. Koenig SC, Woolard C, Drew G, Unger L, Gillars K, Ewert D, et al. Integrated data acquisition system for medical device testing and physiology research in compliance with good laboratory practices. Biomed Instrum Technol. 2004;38: 229-40.

7. Schroeder MJ, Perreault B, Ewert DL, Koenig SC. HEART: an automated beatto-beat cardiovascular analysis package using Matlab. Comput Biol Med. 2004; 34:371-88.

8. Kalavrouziotis G, Karunaratne A, Raja S, Ciotti G, Purohit M, Corno AF, et al. Intra-aortic balloon pumping in children undergoing cardiac surgery: an update of the Liverpool experience. J Thorac Cardiovasc Surg. 2006;131:1382.e1310.

9. Pinkney KA, Minich LL, Tani LY, Di R, Veasy LG, McGough EC, et al. Current results with intraaortic balloon pumping in infants and children. Ann Thorac Surg. 2002; 73:887-91.

10. Davies RR, Russo MJ, Hong KN, O’Byrne ML, Cork DP, Moskowitz AJ, et al. The use of mechanical circulatory support as a bridge to transplantation in pediatric patients: an analysis of the United Network for Organ Sharing database. J Thorac Cardiovasc Surg. 2008;135:421-7.e421.

11. Minich LL, Tani LY, McGough EC, Shaddy RE, Hawkins JA. A novel approach to pediatric intraaortic balloon pump timing using M-mode echocardiography. Am J Cardiol. 1997:80:367-9.

12. Pantalos GM, Minich LL, Tani LY, McGough EC, Hawkins JA. Estimation of timing errors for the intraaortic balloon pump use in pediatric patients. Asaio J. 1999:45:166-71.

13. Bombardini T, Gemignani V, Bianchini E, Venneri L, Petersen C, Pasanisi E, et al. Diastolic time - frequency relation in the stress echo lab: filling timing and flow at different heart rates. Cardiovasc Ultrasound. 2008;6:15.

14. Lu PJ, et al. Wave energy patterns of counterpulsation: a novel approach with wave intensity analysis. J Thorac Cardiovasc Surg. 2011;142:1205-13.

15. Giridharan GA, Bartoli CR, Spence PA, Dowling RD, Koenig SC. Counterpulsation with symphony prevents retrograde carotid, aortic, and coronary flows observed with intra-aortic balloon pump support. Artif Organs. 2012; 36:600-6.

16. Applebaum RM, Wun HH, Katz ES, Tunick PA, Kronzon I. Effects of intraaortic balloon counterpulsation on carotid artery blood flow. Am Heart J. 1998;135: 850-4.
17. Schachtrupp A, Wrigge H, Busch T, Buhre W, Weyland A. Influence of intra-aortic balloon pumping on cerebral blood flow pattern in patients after cardiac surgery. Eur J Anaesthesiol. 2005;22:165-70.

18. Bia D, Zócalo Y, Armentano R, de Forteza E, Cabrera-Fischer E. Acute increase in reversal blood flow during counterpulsation is associated with vasoconstriction and changes in the aortic mechanics. Conf Proc IEEE Eng Med Biol Soc. 2007; 2007:3986-9.

19. Minich LL, Tani LY, Pantalos GM, Bolland BL, Knorr BK, Hawkins JA Neonatal piglet model of intraaortic balloon pumping: improved efficacy using echocardiographic timing. Ann Thorac Surg. 1998;66:1527-32.

20. Gardner RM. Direct blood pressure measurement: dynamic response requirements. Anesthesiology. 1981;54:227-36.

21. Moulopoulos SD. The limits of counterpulsation. Int J Artif Organs. 1993;16: 803-5.

22. Bartoli CR, Dowling RD, Wilson GC, Giridharan GA, Slaughter MS Sherwood LC, et al. Response to letter to the editor: a novel subcutaneous counterpulsation device: acute hemodynamic efficacy during pharmacologically induced hypertension, hypotension, and heart failure. Artif Organs. 2011;35: 93-5.

23. Hawkins JA, Minich L. Mechanical Circulatory Support for Cardiac and Respiratory Failure in Pediatric Patients. New York, NY: Marcel Dekker; 2001.

24. Papaioannou TG, Mathioulakis DS, Nanas JN, Tsangaris SG Stamatelopoulos SF, Moulopoulos SD. Arterial compliance is a main variable determining the effectiveness of intra-aortic balloon counterpulsation: quantitative data from an in vitro study. Med Eng Phys. 2002;24:279-84.

25. Lin CY, Galysh FT, Ho KJ, Patel AS. Response to single-segment intraaortic balloon pumping as related to aortic compliance. Ann Thorac Surg. 1972;13: 468-76.

26. Papaioannou TG, Mathioulakis DS, Stamatelopoulos KS, Gialafos EJ, Lekakis JP, Nanas J, et al. New aspects on the role of blood pressure and arterial stiffness in mechanical assistance by intra-aortic balloon pump: in vitro data and their application in clinical practice. Artif Organs. 2004;28:717-27.

27. Minich LL, Tani LY, Hawkins JA, Bartkowiak RR, Royall ML, Pantalos GM In vitro evaluation of the effect of aortic compliance on pediatric intra-aortic balloon pumping. Pediatr Crit Care Med. 2001;2:139-44.

28. Sharp MK, Pantalos GM, Minich L, Tani LY, McGough EC, Hawkins JA. Aortic input impedance in infants and children. J Appl Physiol. 2000;88:2227-39. 